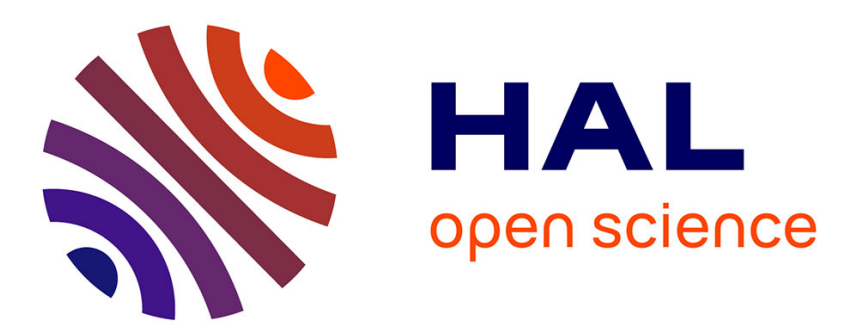

\title{
Polynomial Chaos Representation for Identification of Mechanical Characteristics of Instrumented Structures
}

\author{
Franck Schoefs, Humberto Yáñez-Godoy, Francesca Lanata
}

\section{To cite this version:}

Franck Schoefs, Humberto Yáñez-Godoy, Francesca Lanata. Polynomial Chaos Representation for Identification of Mechanical Characteristics of Instrumented Structures. Computer-Aided Civil and Infrastructure Engineering, 2011, 26 (3), pp.173-189. 10.1111/j.1467-8667.2010.00683.x . hal-01007188

\section{HAL Id: hal-01007188 \\ https://hal.science/hal-01007188}

Submitted on 16 Jun 2014

HAL is a multi-disciplinary open access archive for the deposit and dissemination of scientific research documents, whether they are published or not. The documents may come from teaching and research institutions in France or abroad, or from public or private research centers.
L'archive ouverte pluridisciplinaire HAL, est destinée au dépôt et à la diffusion de documents scientifiques de niveau recherche, publiés ou non, émanant des établissements d'enseignement et de recherche français ou étrangers, des laboratoires publics ou privés.

\section{(c)(1)}

Distributed under a Creative Commons Attribution| 4.0 International License 


\title{
Polynomial Chaos Representation for Identification of Mechanical Characteristics of Instrumented Structures
}

\author{
Franck Schoefs* \\ University of Nantes, Research Institute in Civil Engineering and Mechanics (GeM), UMR CNRS 6183, Faculté des \\ Sciences et des Techniques, 2 rue de la Houssinière, Nantes, F-44000 France \\ Humberto Yáñez-Godoy \\ OXAND S.A., 49 Avenue Franklin Roosevelt 77210 Avon, France and University of Nantes, Research Institute in \\ Civil Engineering and Mechanics (GeM), UMR CNRS 6183, Faculté des Sciences et des Techniques
}

\&

Francesca Lanata

University of Nantes, Research Institute in Civil Engineering and Mechanics (GeM), UMR CNRS 6183, Faculté des Sciences et des Techniques

\begin{abstract}
The modeling of in-service behavior is of first importance when reassessing complex structures like harbor structures and when performing risk analysis. To this aim, the monitoring of structures allows assessment of the level of loading and to provide more realistic models for mechanical behavior or input values for their parameters. Moreover, for complex structures and due to building hazards, a stochastic modeling is needed to represent the large scatter of measured quantities. In this article, a step-by-step procedure for structural identification is presented. A decomposition of random variables on Polynomial Chaos is selected and it is shown to represent better the basic variables in comparison to preselected distribution functions, when considering maximum likelihood estimate. The decomposed variables are used for a stochastic analysis to be further updated with available monitoring data. The model can be used to follow the structure behavior during in-service or extreme
\end{abstract}

*To whom correspondence should be addressed. E-mail: franck. schoefs@univ-nantes.fr. conditions and to perform a reliability analysis. The proposed procedure will be carried out by using available data from the monitoring of a pile-supported wharf in the Port of Nantes, in France, but it can be generalized to similar monitored structures.

\section{INTRODUCTION}

The optimization of Inspection-Maintenance-Reparation of structures in coastal areas is still an actual challenge. In fact, harbors include a set of heterogeneous structures due to their different building periods and manufacturing conceptions with a great variability during design and construction phases (Boéro et al., 2009a, 2009b). Monitoring is the only way to understand both complex interaction mechanisms, as soil-structure interaction (Sundaravadivelu et al., 1999; Donahue et al., 2005), and real in-service structural behavior that is greatly influenced by building conditions and settlements that are expected to make the current and 
the theoretical behaviors different (Martin and Bell, 1999; Del Grosso, 2000; Vallone and Giammarinaro, 2007). Port facilities and wharfs in particular, are subjected to complex loads (ship berthing and mooring, tidal cycles, embankment and wind actions on cranes and ships). A procedure of identification of random variables from structural monitoring in view of updating future reliability studies is proposed here by using real data collected from the monitoring of a pile-supported wharf.

Frequently used since the 1980s, pile-supported wharfs are made up of a reinforced concrete platform supported by a network of metallic-driven piles filled up with concrete; these structures are leaned against a backfill by means of a vertical reinforced concrete backwharf wall and they are anchored behind in the embankment by sloped steel tie-rods. Anchoring rods in a pile-supported container wharf are identified as critical elements for two main reasons: first, their behavior is very sensitive to building conditions and second, they support a great part of horizontal loading due to ships mooring or wind loading on lift-cranes. Moreover, there exists no technique to inspect them in the soil. Therefore, a probabilistic modeling of their behavior is needed for structural reliability and risk analysis during in-service conditions. Monitoring is considered as a proficient tool to suggest less complex but more suitable probabilistic models of these structural elements.

Only a few papers are available in the literature on this field. Most of them suggest monitoring a single or few cross-sections assuming that the scatter with space is low (Delattre and Mespoulhe, 1999; Gattermann et al., 2001; Marten et al., 2004; Moerman et al., 2005). Del Grosso et al. (2000) propose a spatially distributed monitoring of a pier but also in this latter example, no statistical analysis and probabilistic modeling are available.

After discussing the main assumptions for the probabilistic modeling, the work aims to perform stochastic finite element analysis for a typical pile-supported wharf. A comparison between the 3D and 2D mechanical finite models is briefly presented. The identification of mechanical random variables of the models from monitoring data is performed (Beck and Arnold, 1977). As an alternative to the step-by-step inverse identification of basic variables based on the simplex algorithm (Nelder and Mead, 1965) assuming the probability density function as known, a new method based on Polynomial Chaos (PC) identification is suggested here (Perrin et al., 2007; Adeli and Jiang, 2009). The procedure is applied on real data from the monitoring of two pile-supported wharfs in Nantes harbor instrumented in $30 \%$ of typical cross-sections. The monitoring of the first wharf has been already described and discussed by the authors (Yáñez-Godoy et al., 2008b). The instrumenta- tion installed on passive anchoring rods of the second wharf and the available data are described in this article. After that, the collected data are analyzed and a modeling of the stochastic process of tie-rod loading is suggested. A comparison of the results from the two wharfs is also briefly addressed.

\section{MAIN ASSUMPTIONS FOR STOCHASTIC MODELING FROM TIME SERIES}

\subsection{Available data from monitored structures}

For the past decade, control of structural behavior through Non-Destructive Testing (NDT) or monitoring has underlined the need of developing data processing algorithms and structural computation methods. The time histories from a structural monitoring can be classified into three categories:

1. Time series describing the progression of aging phenomena like chloride ingress in concrete and/or crack propagation.

2. Time series measuring the strain affected by nonperiodic loading like wind and truck loading.

3. Time series measuring the strain due to cyclic loading like temperature, tide, or waves.

This article focuses on data obtained from the latter category during the so-called training period that means before in-service conditions and aging mechanisms occur. Moreover, when similar structural elements, placed at a given location $x_{i}$ are monitored (beams [Lanata and Schoefs, 2010] or tie-rods [Yáñez-Godoy et al., 2008b]), and subjected to the same loading, a statistical study of their loading $F\left(x_{i}, t_{j}, \theta_{l}\right)$ can be performed, where $t_{j}$ denotes the instant time and $\theta_{l}$ the event that represents mainly the hazard during building works and density of the nearby ground. Finally, when structural elements in the soil (sheet-piles, piles, rods) are considered, cyclic variation of the water level modifies the ground granular structure with time, that is, the composition of the material. Thus, each loading at time $t_{j}$ can be considered as the loading on the same element in other ground conditions. With this assumption and an abuse of notation, $F\left(x_{i}, t_{j}, \theta_{l}\right)$ can be replaced by $F\left(x_{i}, \theta\right)$. This assumption is built after more than 8 years of data analysis from four wharfs (Yáñez-Godoy et al., 2008b).

\subsection{Mechanical modeling}

The aim of the mechanical modeling is to provide a transfer function $\mathscr{M}$ between the measured loading $F\left(x_{i}, \theta\right)$ and the response of each structural element in terms of random variables to be further updated. Let us 
denote with $k\left(x_{i}, \theta\right)$ the vector of the set of random mechanical parameters for the mechanical relationship $\mathscr{C l}$ and $F_{r}\left(x_{i}\right)$ the boundary conditions expressed in terms of deterministic external loadings for each loading condition. Thus, Equation (1) states the stochastic problem to be solved

$$
\mathscr{C}\left(k\left(x_{i}, \theta\right), F_{r}\left(x_{i}\right)\right)=F\left(x_{i}, \theta\right)
$$

where $k\left(x_{i}, \theta\right)$ is the unknown random variable and $F\left(x_{i}\right.$, $\theta)$ is known only through its realizations $F\left(x_{i}, \theta_{l}\right)$. When a unique random variable $k(\theta)$ is able to describe the behavior of each structural element, Equation (1) simplifies

$$
\mathscr{M}\left(k(\theta), F_{r}\left(x_{i}\right)\right)=F\left(x_{i}, \theta\right)
$$

The aim of the mechanical modeling is to obtain a set of realizations $k\left(\theta_{l}\right)$ by knowing $F\left(x_{i}, \theta_{l}\right)$.

\section{PROBABILISTIC MODELING USING POLYNOMIAL CHAOS}

\subsection{Formulation of the identification problem}

When the distribution function of the random variable $k(\theta)$ does not follow a predefined probability density function and the input uncertainties are large, probabilistic uncertainty quantification methods need to be used to propagate uncertainty from model inputs to outputs (Moaveni et al., 2009). The probabilistic modeling is also very useful when the identification procedure from a database has to be standardized.

Two broad classes of uncertainties can be defined: epistemic or reducible uncertainties that stem from lack of knowledge or data and aleatory or irreducible uncertainties, related to the inherent randomness of the process (Matthies, 2007). The epistemic uncertainty can be assessed using knowledge or probabilistic representations. The knowledge representation includes, for example, fuzzy set theories (Adeli and Jiang, 2006), interval analysis (Muhanna et al., 2007), or evidence theory (Bae et al., 2004), while the probabilistic representation assesses the uncertainty from a Bayesian point of view (Igusa et al., 2002; Cheung and Beck, 2010). The most appropriate mathematical representation of aleatory uncertainty is the probabilistic framework when the given information is perfect and complete, for example, by using random variables or stochastic processes. To this purpose, the Monte Carlo approach can be employed but it is computationally expensive and is only used as the last resort. The sensitivity method is a more economical approach, based on the moments of samples, but it is less robust and depends strongly on the modeling assumptions. One popular technique is the perturbation method where all the stochastic quantities are expanded around their mean via Taylor series. This approach, however, is limited to small perturbations and does not readily provide information on high-order statistics of the response. Another approach is based on expanding the inverse of the stochastic operator in a Neumann series, but this too is limited to small fluctuations, and even combinations with the Monte Carlo method seem to result in computationally prohibitive algorithms for complex systems.

A more effective approach pioneered by Ghanem and Spanos (2003) in the context of finite elements for solid mechanics is based on a spectral representation of the uncertainty. This allows high-order representation, not just first-order as in most perturbation-based methods, at high computational efficiency. It is based on the theory of homogeneous chaos. PC methods employ the PC expansion, which is a global polynomial expansion in probability space in terms of independent random variables and deterministic coefficients. The fundamental concept on which PC decompositions are based is to regard uncertainty as generating a new dimension and the solution as being dependent on this dimension. A convergent expansion along the new dimension is then sought in terms of a set of orthogonal basis functions, whose coefficients can be used to quantify and characterize the uncertainty. The motivation behind PC approaches includes its suitability to models expressed in terms of partial differential equations, the ability to deal with situations exhibiting steep nonlinear dependence of the solution on random model data, and the promise of obtaining efficient and accurate estimates of uncertainty. In addition, such information is provided in a format that permits it to be readily used to probe the dependence of specific observables on particular components of the input data and to design experiments in order to better calibrate or test the validity of postulated models. Finally, reliability analyses can easily be performed on the basis of the representation of random variables with PC decomposition.

\subsection{Variable identification by using $\mathrm{PC}$ representation}

Let us consider a random sample $\left\{k\left(\theta_{l}\right)\right\}_{l=1}^{M}$ of a mechanical parameter $k$ with $M$ values. To systematize the identification of the random variable $k(\theta)$, a representation with PC decomposition is chosen. The selected estimator of fitting is the maximum likelihood (Desceliers et al., 2007). The purpose of this procedure is to identify the coefficients $k_{i}$ of the one-dimensional PC decomposition for the random variable $k(\theta)$ from $M$ samples noted by $\left\{k\left(\theta_{l}\right)\right\}_{l=1}^{M}$. The chaos decomposition of the 
random variable is written as

$$
k(\theta)=k(\xi(\theta))=\sum_{i=0}^{p} k_{i} h_{i}(\xi(\theta))
$$

where $p$ is the order of the PC decomposition, $\xi(\theta)$ the Gaussian germ, that is, a standardized normal variable, and $h_{i}$ the Hermite polynomial of degree $i$.

By using the maximum likelihood method, coefficients $k_{i}$ are the solution of the optimization problem

$$
\boldsymbol{\kappa}=\underset{\kappa}{\operatorname{argmax}} L(\boldsymbol{\kappa})
$$

where $\boldsymbol{\kappa}$ is the vector of coefficients $k_{i}\left(\kappa=\left[k_{0}, \ldots, k_{p}\right] \in\right.$ $\left.\mathbb{R}^{p}\right)$ with dimension $(p+1)$, and $L$ is the likelihood function

$$
L(\boldsymbol{\kappa})=\prod_{l=1}^{M} p_{k}\left(k\left(\theta_{l}\right) ; \boldsymbol{\kappa}\right)
$$

where $M$ is the size of the sample of $k(\theta)$ (see Section $7.3, \Sigma m=85)$ and $p_{k}\left(k\left(\theta_{l}\right) ; \kappa\right)$ is the probability density function of the variable $k(\theta)$ depending on the set of PC coefficients. This probability is estimated by using a single kernel smoothing method from $10^{6}$ points that gives a good estimate with respect to the available memory of the computer.

\subsection{Algorithm for solving the optimization problem}

As the likelihood function in Equation (5) takes very fair values very close to the numerical precision, the optimization problem in Equation (4) is modified into

$$
\kappa=\underset{\kappa}{\operatorname{argmin}}(-\log (L(\kappa)))
$$

To systematize the algorithm, Desceliers et al. (2007) suggest reducing the optimization problem by stating conditions (Ghanem and Spanos, 2003)

$$
\left\{\begin{array}{l}
k_{0}=\mu_{k} \\
\operatorname{Var}(k(\xi(\theta)))=\sum_{i=1}^{p} k_{i}^{2}=\sigma_{k}^{2}
\end{array}\right.
$$

where $\mu_{k}$ and $\sigma_{k}$ are, respectively, the statistical average and standard deviation of variable $k(\theta)$, computed from the experimental sample of $k(\theta)$ in Section 7.3. The first condition reduces the number of unknown PC coefficients to $p$ and the second one allows searching other coefficients on a hypersphere in $\mathbb{R}^{p}$ with radius $\sigma_{k}$. Moreover, by denoting with $k_{i}^{*}$ the ratio $k_{i} / \sigma_{k}$, the second condition of Equation (7) becomes

$$
\sum_{i=1}^{p}\left(k_{i}^{*}\right)^{2}=1
$$

This new condition allows searching $p$ coefficients $\left[k_{1}^{*}, \ldots k_{i}^{*}, \ldots, k_{p}^{*}\right]$ on a hypersphere with radius 1 . This last condition is interesting for the optimization process. A two-step flowchart optimization is considered for solving Equation (6) by knowing condition (7).

1. A first localization of the minimum of $-\log (L(\kappa))$ is found through Monte Carlo simulations (size 100 and 1,000, respectively, for PC of order 2 and 3).

2. Starting from this point, the simplex method proposed by Nelder and Mead (1965) is used. Lagaris et al. (1998) have demonstrated that the method has very good convergence rates in low-dimension spaces.

This process allows avoiding a pseudoconvergence around maximum values. It is possible to parameterize the hypersphere by using angular parameters to localize the minimum of the likelihood function, as shown in Section 7.4.

\section{DESCRIPTION OF THE MONITORED WHARF}

\subsection{Structural description}

The structure under study is the extension of the timber terminal of Cheviré, the station 4, named Cheviré-4 wharf in the following. The Cheviré-4 wharf is located downstream from the Cheviré bridge near Nantes city (west of France), in a fluvial ambiance, in the left strand of the river Loire. It is $180 \mathrm{~m}$ long and $34.50 \mathrm{~m}$ wide. The wharf is planned to receive ships, maximum 225$\mathrm{m}$ long and 9.10-m draught. The collaboration with the Port Authority of Nantes Saint-Nazaire (PANSN) permitted the survey of the structure.

The construction of the wharf spread out over 1 year and 2 months, from October 2002 to December 2003. The wharf has been built from the upstream to the downstream direction. The construction phases include: preliminary works, the driving of the piles, the driving of the sheet-pile wall, concreting the back-wharf wall and inside the piles, installing the prefabricated elements of the platform, concreting the platform, implementing and compacting the backfill, laying down the rods following the advancement of the backfill, banking up, ending works, and fittings. The platform is assumed to be waterproof due to the realized drainage system, so that rainfall does not modify the water level in the embankment.

The Cheviré-4 wharf is built on a network of 198 driven-metallic piles filled up with concrete in the upper side, about $33 \mathrm{~m}$ long and with an outside diameter of 711, 762, or $863 \mathrm{~mm}$ depending on their position. 


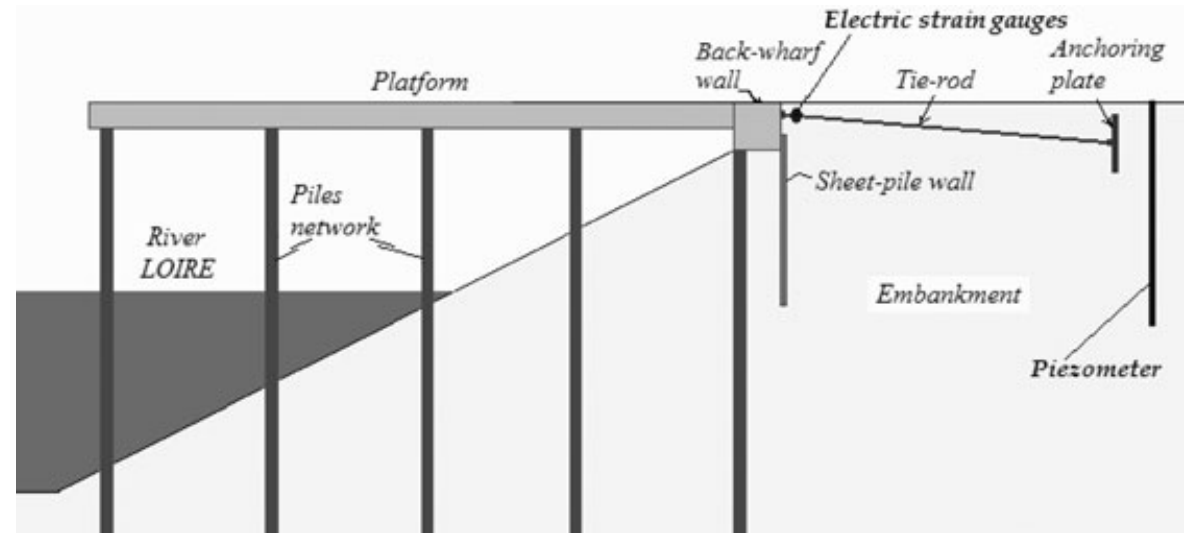

Fig. 1. Cross-section of the wharf.

Capitals destined to center the load on the piles are placed on the head of each pile. A $0.35-\mathrm{m}$ high concrete deck is put down on a network of 1.35 -m high reinforced concrete T-shape beams, themselves supported by the piles. The wharf is anchored by 37 passive-sloped tierods, steel cylinders ( $75 \mathrm{~mm}$ diameter and $15 \mathrm{~m}$ long), behind every line of piles. These tie-rods are anchored in the back-wharf wall ( $2.20 \mathrm{~m}$ high) by means of a connecting rod, and at the other end in a reinforced concrete anchoring plate, $2.6 \mathrm{~m}$ high and wide and $0.5 \mathrm{~m}$ thick. Behind the back-wharf wall, a vertical 9-m high sheet-pile wall prevents the leakage of the small particles from the backfill; this curtain is linked to the backwharf wall at its crest. The back-wharf wall is crossed by drainage channels at a height of $6.7 \mathrm{~m}$ (level indicated in marine cards spot height M.C.; the zero of the marine cards corresponds to the level of the lowest possible theoretical tide). A sketch of a typical cross-section and main elements is presented in Figure 1. Each element plays a specific role in the behavior of the pile-supported wharf in a functional context.

\subsection{Design criteria and main assumptions: need for instrumentation for a better understanding}

Only quasi-static behavior was considered for the design of the wharf. Loading conditions include: (1) vertical loading coming from the own weight of the structure, the cranes and the service loading and (2) horizontal loading coming from the embankment loading on the back-wharf wall, the variations of water level, the ship berthing, the ship mooring and the wind actions on the cranes.

For the design under horizontal loading, these types of wharfs are usually modeled by means of a $2 \mathrm{D}$ structure similar to a porch (in a cross-section such as represented in Figure 1). In this way, lateral elastic reactions of the different ground layers on the piles are sketched by a series of springs and the supports of the piles are modeled with toggle joints, supposed to be as perfect embeddings or elastic embeddings (Ananthanathan et al., 2000). Then, displacements, deformations, and stresses in the piles and in different points of the platform are computed. The above modeling leads to obtaining global stiffness for each corresponding row of piles; immediately afterward, these rigidities are modeled like elastic supports of an infinitely rigid beam that is analyzed for different horizontal loading situations. That allows determining the transversal reactions of each row of piles for each loading situation.

The main usual hypotheses come from expert criteria and from studies of uncertainty accomplished during the preparation of the European semiprobabilistic code called Eurocode 7 (Magnan, 2006) and related to the new seismic design codes (Nozu et al., 2004; Madhuri et al., 2007). Experts' opinion on design of wharfs leads to several statements: (1) the tie-rods are prestressed and they are loaded by the platform depending on the platform deformation only and (2) immediately after construction, loadings on the vertical reinforced concrete anchoring plate embedded inside the bank are sufficient to assume that the passive earth pressure is totally acting, so that the limit state is reached. More details are reported in Verdure (2004).

The article is focused on loading where hazards and uncertainties play the most important role, that is horizontal loading and especially the loading acting from the bank to the river. In fact, this latter loading is the source of the most sensitive damages in structures, particularly the relative displacement between the platform and the embankment that leads to cracks in the pavement. According to the analyzed loading conditions, tie-rods and lateral capability of the piles are highly loaded. Accomplished studies in Magnan (2006) have shown a great variance reduction on piles lateral loading due to the great stiffness of the platform: hazards on pile behavior, 
that are assumed to be without any correlation, are then slightly transferred. Also, the variance of earth pressure loading is reduced or even cancelled due to the high inertia of the back-wharf wall (Verdure et al., 2005). On the other hand, a great hazard still lies on the computation of the tie-rods behavior. That is why a monitoring of the tie-rods has been carried out during the construction of the wharf.

\subsection{Monitoring setup}

A monitoring strategy has been achieved, which aims to: (1) follow the global behavior of the wharf within the next 5 years after the construction to set up models for the prediction of the behavior evolution in time; (2) base the maintenance policy on a better understanding of the in-service behavior; (3) find the main variables that influence the behavior; and (4) perform reliability analysis during extreme events (storms) for in-service structures (Yáñez-Godoy et al., 2006). A complete description of this strategy and its application to four wharfs is available in Schoefs et al. (2004).

The objective being the understanding of the wharf behavior under horizontal loading-actions of the embankment, ship berthing and wind action on the cranes-it was decided to monitor the tie-rods for two reasons: they are the most sensitive elements of the wharf and they are no longer accessible after the construction. Additional information like the displacements of the wharf, the tide level, and the underground water level in the embankment are available also after the construction.

The wharf has been instrumented on 12 tie-rods (regularly distributed along the length of the wharf, see Figure 2) to follow the normal load in the rods crosssection. To this purpose, electrical strain gauges have been mounted in full bridge and bonded to the rods with a high-temperature epoxy resin used for sensors manu- facturing; the gauges are linked to a Campbell Scientific CR10X data logger (Campbell Scientific Inc., Logan, UT). The wiring of strain gauges in a full bridge ensures a temperature self-compensation. The system also ensures the corrosion protection of the rods. The instrumented rods are identified using the letter " $\mathrm{R}$ " with their longitudinal abscissa position $x$ in meters. By convention, $x=0$ denotes the upstream extremity of the wharf.

In addition, three piezometers, two at the ends and one in the middle wharf, are implanted behind the backwharf wall (until a depth of about $6 \mathrm{~m}$ ) and linked to the data logger, to measure the underground water level in the embankment (Figure 2). As another wharf is connected at the upstream side, piezometers at abscissa 0 and 80 give the same measurements of water level. For this reason, in the following only these two piezometers will be considered for characterizing the water level without the boundary effects that affect the piezometer at abscissa 175 .

Finally, a tidal gauge (controlled by the PANSN) measures the real tide level every 5 minutes; the tidal gauge is located about $1 \mathrm{~km}$ downstream from the Cheviré bridge. These measurements allow taking into account the overcrests, due to the air pressure, the rate of the river flow, and the wind action during the data processing.

\section{DATA ANALYSIS, STOCHASTIC MODELING, AND POSTPROCESSING}

\subsection{Available data}

The aim of the data processing phase is the characterization of the behavior of the set "Soil-Rod-Anchoring Plate" called SRAP in the following. The main steps are: (1) data collection provided by the monitoring devices, (2) analysis of the rough data and understanding of their

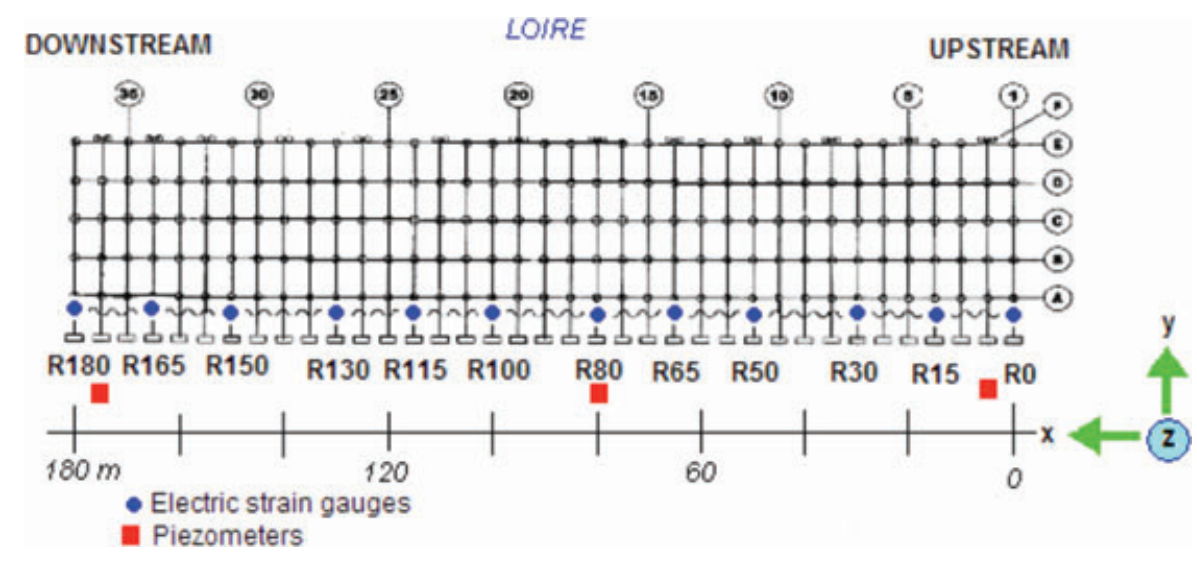

Fig. 2. Plan view of the installed instrumentation. 
physical meaning, and (3) data processing to highlight significant correlations. A first analysis of data and the comparison with another wharf is available in YáñezGodoy (2008) and Yáñez-Godoy et al. (2008b). Some considerations on the results from both wharfs will be addressed at the end of this article.

The measurement campaigns are scheduled every 30 minutes, ensuring to follow the tide effects without involving a too important storage capacity (the current capacity permits storage of about 3 months of data). The rough signals stored by the acquisition system provide the local physical measurements, which are electric voltages. A classical preprocessing of the measurements is necessary to have the normal load in the monitored tierods (Yáñez-Godoy, 2008).

Time series collected from each instrumented tie-rod are available from 2003 to 2005 . Measurements stored in 2003 are relative to the construction steps. In this article, an interval of 2 years from January 2004 to October 2005 is analyzed, during which no changes in the behavior of the wharf have been observed (Yáñez-Godoy et al., 2008b).

\subsection{Reduction of stochastic complexity: ergodicity}

To characterize the SRAP behavior, the random load normal to the cross-section in tie-rods at position $x_{i}$ and instant time $t_{j}, F\left(x_{i}, t_{j}, \theta\right)$ is considered. Measurements from sensors are the discrete realizations $F\left(x_{i}, t_{j}, \theta_{l}\right)$ of this time-dependent stochastic process. As no changes of the behavior of the wharf were observed during the monitoring period under study, the stochastic process of the loading variation is assumed to be stationary and ergodic with time. The identification of the marginal distribution of the stochastic process $F\left(x_{i}, t_{j}, \theta\right)$ (marginal with respect to time) has to be addressed. Measurements at different instant times of this process are then considered as events of a stochastic process with respect to space only. With an abuse of notation, this stochastic process will be denoted by $F\left(x_{i}, \theta\right)$ in the following. It follows that each realization $F\left(x_{i}, \theta_{l}\right)$ of this variable comes from a measurement at a given time.

To simplify the future treatments of data and the identification of variables, $F$ is written as the summation of a permanent deterministic external loading $F_{r}$ with a variable loading due to environment and ships actions $F_{e}$

$$
F\left(x_{i}, \theta\right)=F_{r}\left(x_{i}\right)+F_{e}\left(x_{i}, \theta\right)
$$

Note that $F_{r}\left(x_{i}\right)$ represents the permanent load measured at the abscissa $x_{i}$ due to the pressure of the embankment on the wharf $F_{R}$ only, and $F_{e}\left(x_{i}, \theta\right)$ is the component of the loading due to the tide level denoted TL: in fact, data presented here refer to the period of nonexploitation (no ships action) and they can be considered as representative of the loading due to tide levels only. This is due to the displacement $u\left(x_{i}\right)$ of the wharf from the equilibrium position under the load $F_{T L}$. This value is strongly dependent on the tie-rods stiffness $k\left(x_{i}, \theta\right)$, so that it can be simplified as $F_{e}\left(x_{i}, \theta\right)=k\left(x_{i}, \theta\right) u\left(x_{i}\right)$. This decomposition avoids the resolution of an inverse stochastic problem with a huge number of parameters and variables.

Note that a linear behavior of tie-rods is hypothesized here: this assumption is reasonable due to the small displacements of the wharf. In the following, the mechanical behavior of all the tie-rods is considered to be characterized by the same random variable $k(\theta)$. As a matter of fact, this parameter is variable for each tie-rod due to both construction uncertainties (laying down of the tierods) and natural hazard of the embankment (Verdure, 2004; Yáñez-Godoy, 2008). This assumption means that even if the initial loading of tie-rods strongly depends on the construction conditions, the variation of loading after few months and tide cycles does not depend on the tie-rod position. Then Equation (9) can be simplified as

$$
F\left(x_{i}, \theta\right)=F_{r}\left(x_{i}\right)+k(\theta) u\left(x_{i}\right)
$$

Finally, the transfer function of Equation (2) can be detailed as follows

$$
\mathscr{M}\left(k(\theta), F_{r}\left(x_{i}\right)\right)=F_{r}\left(x_{i}\right)+k(\theta) u\left(x_{i}\right)
$$

\subsection{Use of periodic measured loading for identification}

The periodic variation of the tide level is used as a natural cyclic loading on the wharf. During a falling tide, the loading on the wharf that is in the tie-rods, is increasing. The decreasing of water level in the river during a half cycle of tide is defined as $\Delta H\left(\Delta H=H_{\max }-\right.$ $\left.H_{\text {min }}\right)$. The water levels $H_{\max }$ and $H_{\min }$ are measured at time instants $t_{\min }$ and $t_{\max }$, respectively, that represent the beginning and the end of a half cycle of tide. In the following, falling tides where the maximum level of water $H_{\max }=H\left(t_{\min }\right)$ induces the minimum loading in the tie-rods will be considered.

The sensitivity of normal load $\Delta F\left(\Delta F=F\left(x_{i}\right.\right.$, $\left.\left.t_{\max }, \theta_{l}\right)-F\left(x_{i}, t_{\min }, \theta_{l}\right)\right)$ to a given decrement of water $\Delta H\left(\theta_{l}\right)$ allows characterizing the $S R A P$ behavior from Equation (11). Yáñez-Godoy (2008) has shown that the sensitivity scatter in time upon the set of instrumented rods is very fair for high levels of loading that occur during high-tide levels $\left(\mathrm{CMAR}^{1}>80\right)$. According to the Tides Annual, ${ }^{2}$ CMAR values vary in the following way: 115 for mean higher high water, 95 


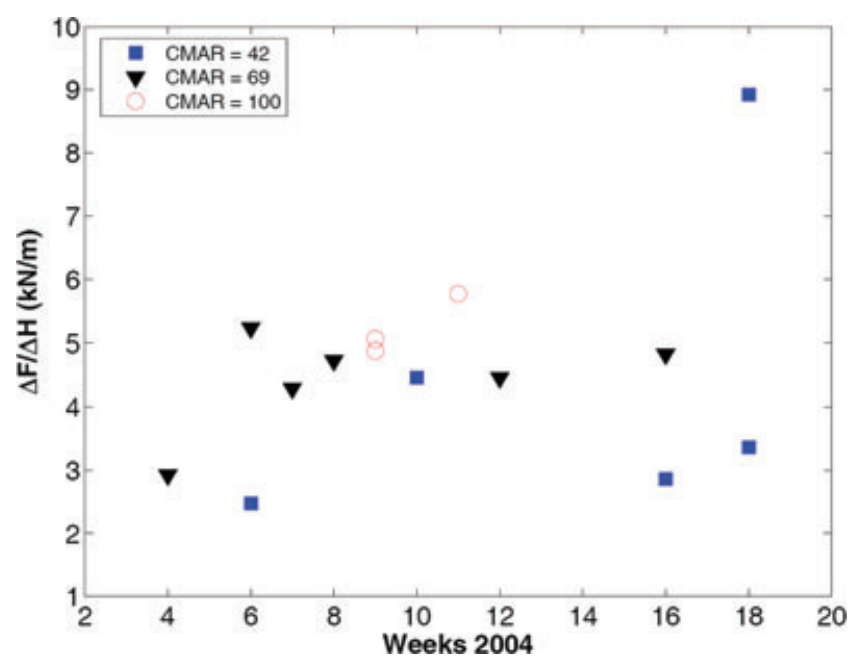

Fig. 3. Variation of the measured normal load $\Delta \mathrm{F}$ in the tie-rod $\mathrm{R} 0$ in relation to water-level variation of the river

Loire $\Delta \mathrm{H}$ for a falling tide $(\mathrm{CMAR}=42,69,100)$.

for mean high water, 70 for mean tide level, 45 and 35 for mean low water. Figure 3 represents the variation of the sensitivity with time (number of the weeks in 2004) for a given tie-rod (R0) and three different coefficients CMAR $(42,69,100)$. These three coefficients are selected because they are representative of different loading condition, approximately corresponding to mean low water values, mean tide level and mean high water, respectively. In addition, the selection is related to the number of available measurements inside each CMAR value. A high scatter is observed for CMAR = 42, while the $S R A P$ seems to reach a stable behavior when the loading variation increases. The aim of the article is to provide a probabilistic model for reliability analysis of wharfs during extreme events like storms that occur mainly in winter when CMAR are higher. As a consequence, in the following, the SRAP behavior will be more deeply investigated for high CMAR only. Regarding the low tide levels, when phenomena seem to be more complex, $\Delta H$ is probably no more sufficient to explain the loading variation in tie-rods. For lower CMAR, another transfer function $\mathscr{M}$ (Equation (2)) should be selected to take into account additional parameters.

Under these conditions, the relationship between $\Delta F\left(x_{i}, \theta\right)$ and the variation of the level of water $\Delta H(\theta)$ is linear. Figure 4 shows the trend of normal load in several tie-rods during a falling tide having $\mathrm{CMAR}=100$. In the following and to simplify the data analysis, the relationship between $\Delta F\left(x_{i}, \theta\right)$ and the variation of the level of water $\Delta H(\theta)$ is assumed to be approximately constant on a certain range $R_{\Delta H}$. To identify the corresponding ranges, values of the coefficients CMAR from

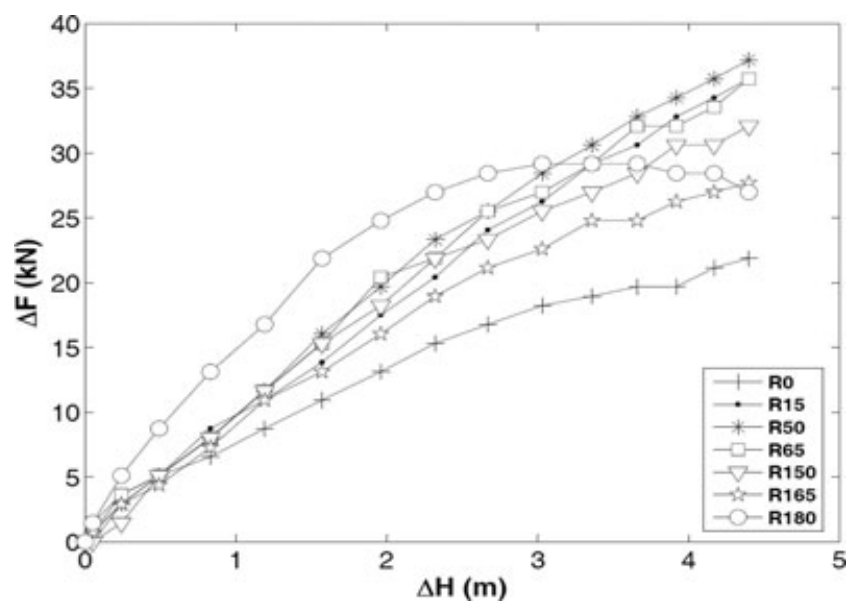

Fig. 4. Variation of the measured normal load $\Delta \mathrm{F}$ in the tie-rods $\mathrm{Ri}$ in relation to water-level variation of the river Loire $\Delta \mathrm{H}$ for a falling tide $(\mathrm{CMAR}=100)$.

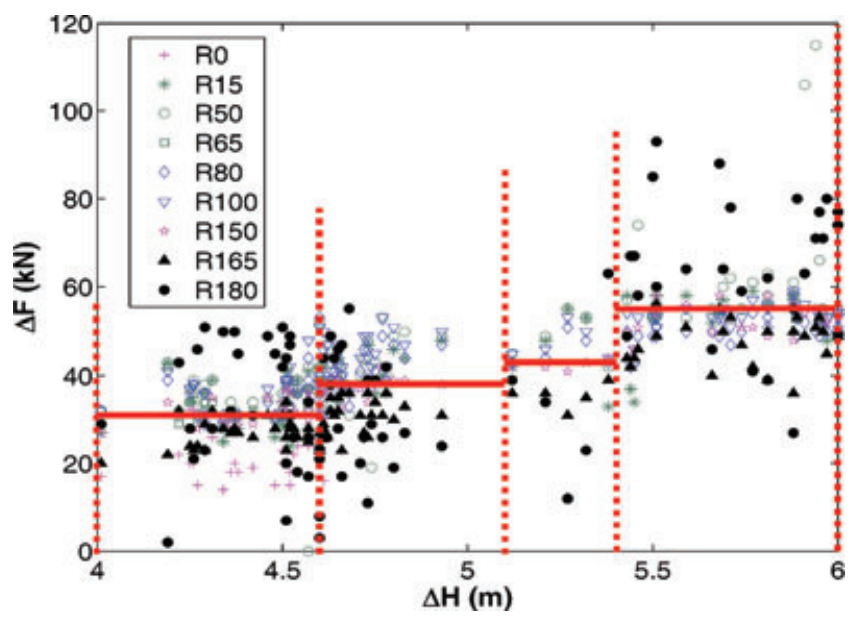

Fig. 5. Variation of the measured normal load in the tie-rods $\mathrm{Ri}$ versus water-level variation of the river Loire during falling tides (CMAR from 95 to 111).

95 to 111 are selected. ${ }^{3}$ Figure 5 shows the plot of $\Delta F$ versus $\Delta H$ for the whole set of instrumented tie-rods during high tide levels in the period from January 2004 to October 2005. Ranges $R_{\Delta H}$ are identified using the criteria that the mean variation inside the range is less than $10 \%$. This value is selected by using a least squares method. Values of $\Delta F\left(R_{\Delta H}\right)$ are given in Table 1.

\subsection{Data postprocessing}

Let us consider the variable loading variation for each $R_{\Delta H}$ during high tides. Figure 6 shows that there is a small variation of the expectation of $\Delta F$ along the wharf. To cancel this effect on the expectation $\overline{\Delta F}\left(x_{i} \mid R_{\Delta H}\right)$ of the random variable $\Delta F\left(x_{i}, \theta \mid R_{\Delta H}\right)$, a 
Table 1

Constant values of $\Delta F$ in each range $R_{\Delta H}$

\begin{tabular}{lcc}
\hline Range & $\overline{\Delta F}\left(R_{\Delta H}\right)[k N]$ & $R_{\Delta H}$ : Range of $\Delta H[m]$ \\
\hline 1 & 32 & {$[4.00 ; 4.60]$} \\
2 & 38 & {$[4.61 ; 5.10]$} \\
3 & 43 & {$[5.11 ; 5.40]$} \\
4 & 55 & {$[5.41 ; 6.00]$} \\
\hline
\end{tabular}

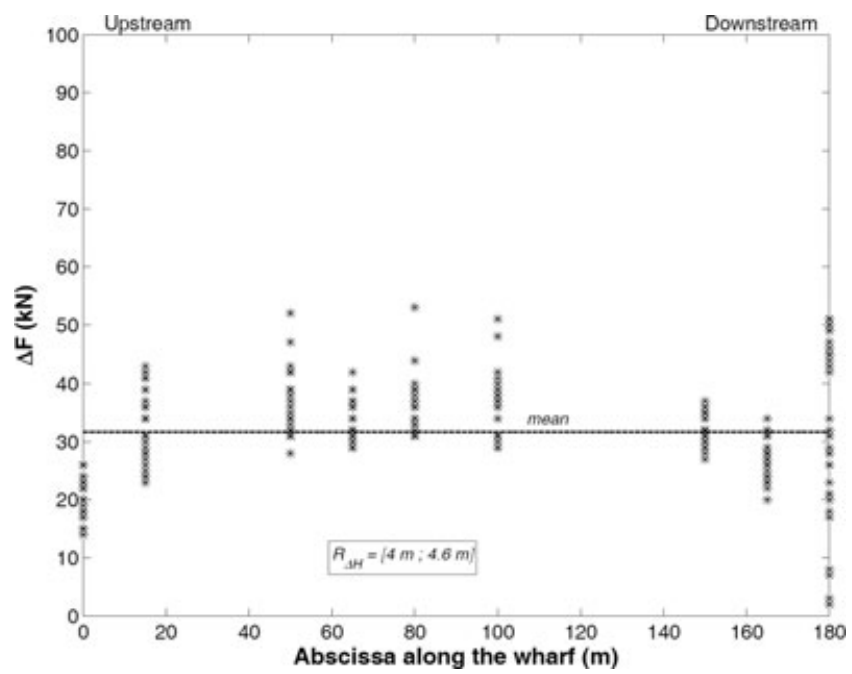

Fig. 6. Variation of the measured loads in the tie-rods along the wharf according to a range of the water-level variation of the river Loire during high-coefficient falling tides

$$
\left(R_{\Delta H}=[4 \mathrm{~m} ; 4.6 \mathrm{~m}]\right) \text {. }
$$

postprocessing of the samples is performed. This observed bias is probably due to the fair size of samples and the error of measurement, which is around $10 \mathrm{kN}$.

The spatial average of the expectation $\overline{\Delta F}\left(x_{i} \mid R_{\Delta H}\right)$ for a given $R_{\Delta H}$ and $n$ instrumented tie-rods can be written as $\frac{1}{n} \sum_{i=1}^{n} \overline{\Delta F}\left(x_{i} \mid R_{\Delta H}\right)$. Note that it equals $\overline{\Delta F}\left(R_{\Delta H}\right)$ in Table 1 . For example, for the first range of interval $\Delta H$, it assumes the value $32 \mathrm{kN}$.

$$
\begin{aligned}
\overline{\Delta F}\left(R_{\Delta H}\right) & =\frac{1}{n} \sum_{i=1}^{n} \overline{\Delta F}\left(x_{i} \mid R_{\Delta H}\right) \\
& \cong \frac{1}{n} \sum_{i=1}^{n} E\left(\Delta F\left(x_{i}, \theta \mid R_{\Delta H}\right)\right)
\end{aligned}
$$

By denoting with $\Delta F^{*}\left(x_{i}, \theta \mid R_{\Delta H}\right)$ the centered random variable associated to $\Delta F\left(x_{i}, \theta \mid R_{\Delta H}\right), \Delta F\left(x_{i}\right.$, $\left.\theta \mid R_{\Delta H}\right)$ is redefined by replacing $\overline{\Delta F}\left(x_{i} \mid R_{\Delta H}\right)$ with $\overline{\Delta F}\left(R_{\Delta H}\right)$ as follows

$$
\Delta F\left(x_{i}, \theta \mid R_{\Delta H}\right) \cong \Delta F^{*}\left(x_{i}, \theta \mid R_{\Delta H}\right)+\overline{\Delta F}\left(R_{\Delta H}\right)
$$

Figure 7 shows realizations of this filtered $\Delta F\left(x_{i}\right.$, $\left.\theta \mid R_{\Delta H}\right)$ for $R_{\Delta H}=[4 \mathrm{~m} ; 4.6 \mathrm{~m}]$ during high tides.

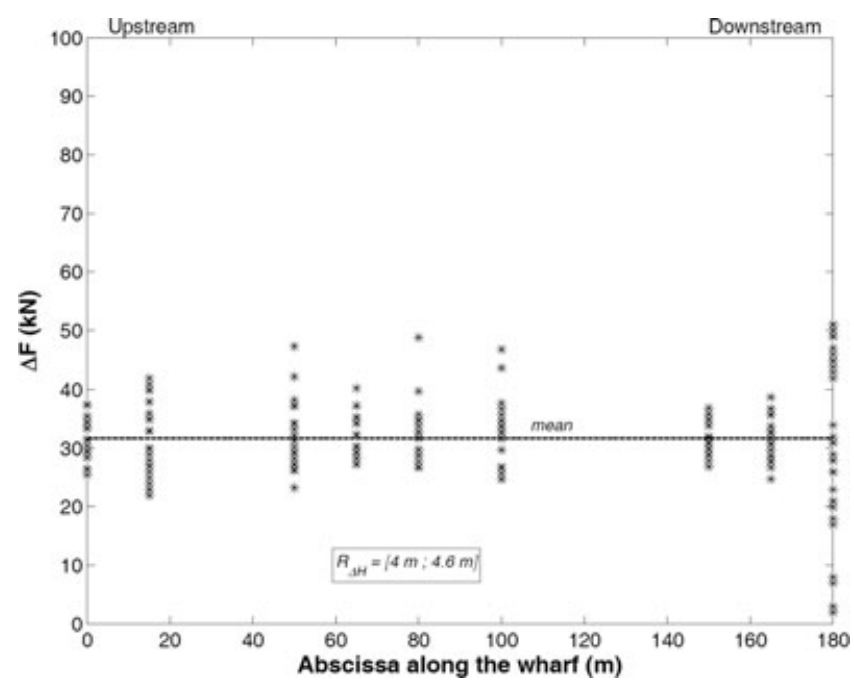

Fig. 7. Variation of the filtered measured loads in the tie-rods along the wharf according to an interval of the water-level variation of the river Loire during high-coefficient falling tides $\left(R_{\Delta H}=[4 \mathrm{~m} ; 4.6 \mathrm{~m}]\right)$.

\section{MECHANICAL MODELING}

Two mechanical models have been developed to represent the spatial behavior of the wharf under the action of horizontal loading: the first one is based on a $3 \mathrm{D}$ finite-element meshing and the second one is an equivalent 2D model.

\subsection{Tridimensional model}

The 3D model is represented in Figure 8. The following elements are selected to take into account the main constitutive elements of the structure: (1) network of reinforced concrete $\mathrm{T}$-shape beams, modeled by bar elements; a tensile stress as a result of the applied dominant load is assumed, while the bending stiffness is included in the bending capacity of the deck; (2) reinforced concrete deck, modeled by shell elements; its tensile load stiffness (in $\vec{e}_{x}, \vec{e}_{y}$ plane) is close to the real one and its bending stiffness ( $\vec{e}_{x}$-and $\vec{e}_{y}$-axis) takes into account the contribution of the network of reinforced concrete T-shape beams, of the berthing beam and of the back-wharf wall; (3) berthing beam, modeled by bar elements; (4) back-wharf wall, modeled by shell elements; (5) piles, modeled by beams with Winkler model for taking the soil-pile interaction into account; and (6) tie-rods, modeled by bar elements, rods are supposed to be simply supported on the back-wharf wall, while the other end can be subjected to given displacements.

The 3D model allows changing the level of complexity to be considered in the modeling and evaluating the 


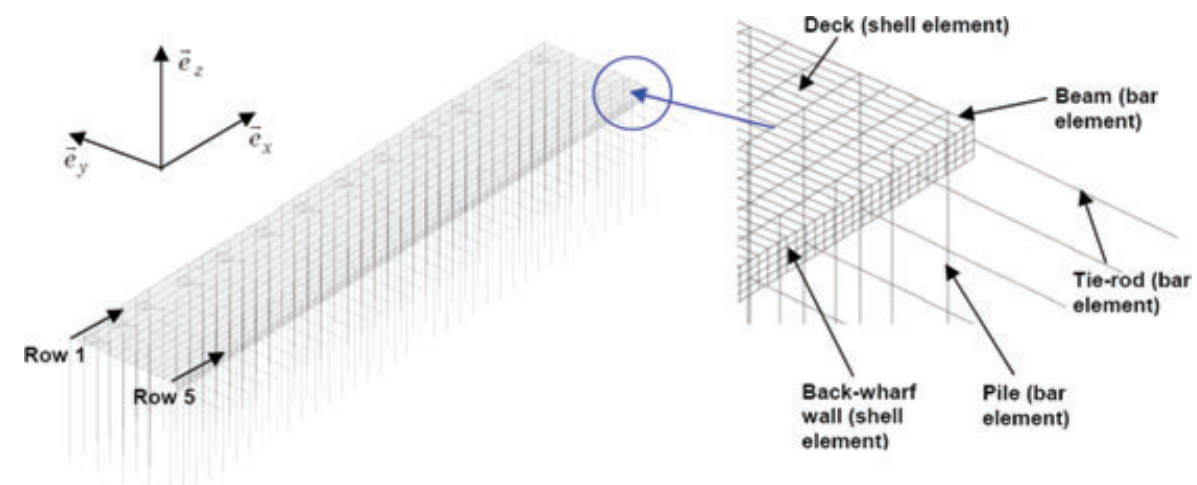

Fig. 8. Geometry of the 3D model.

role of every element. The proposed model has the following levels of complexity:

1. For the 3D finite element model of the deck, the percentages of the relative stiffness for $\vec{e}_{z}$-axis bending are assumed to be the $31 \%$ for the slab (deck), the $6 \%$ for the beams network, and the $63 \%$ for the berthing beam and the back-wharf wall.

2. For the pile modeling, the following percentages of stiffness for $\vec{e}_{x}$-axis bending for each row of piles and rods are obtained: $50 \%$ for the tie-rods and $5 \%, 2 \%, 8 \%, 8 \%$, and $27 \%$ for the Rows 1 to 5 , respectively (see Figure 8). Concerning the relative stiffness, Row 5 is loaded by $54 \%$ of the horizontal loading on the network piles, while Row 1 has a notable increase of stiffness regarding Row 2 due to the presence of a net of beams of variable section placed between these two rows; these beams are distributed alternately along the wharf, they are loaded by the forces coming from the cylindrical defenses on the berthing beam and they are supported by piles of great inertia. The effect of stiffness for $\vec{e}_{y}$-axis bending is negligible.

\subsection{Simplified beam model for simulations (bidimensional model)}

The 3D model presented in the previous section is considered as the reference model, but a simpler model is chosen for further analysis to decrease computation time. Reliability of the wharf subjected to extreme events is to be evaluated. As the structure has a great stiffness, displacements are very low also during extreme events and a linear model is considered sufficiently reliable (Yáñez-Godoy et al., 2008c). The 2D model is based on Timoshenko beam theory (see Figure 9) and it is used as $\mathscr{M}$ model in Equation (11). The parameters of this simplified model are identified from the 3D model. Results are:

1. The platform is modeled by a Timoshenko beam with bending stiffness $1.53 \times 10^{14} \mathrm{~N} / \mathrm{m}^{2}$ and shear stiffness $9.91 \times 10^{10} \mathrm{~N}$.

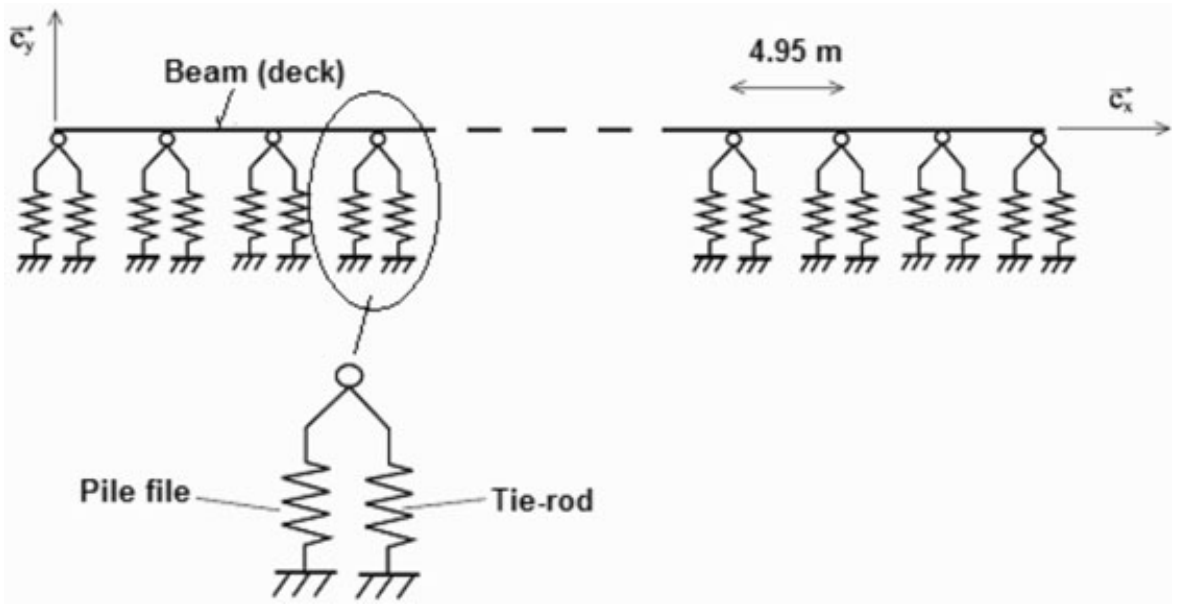

Fig. 9. Equivalent Timoshenko beam model (simplified 2D model). 
2. Each row of piles in the horizontal plane $\left(\vec{e}_{x}\right.$ and $\vec{e}_{y}$ ) is modeled by an $\vec{e}_{y}$-axis spring with stiffness 58.54 and $73.17 \mathrm{MN} / \mathrm{m}$; the latter value corresponds to the rows where beams of variable section mentioned in the previous section exist. Stiffness values are retrieved from the 3D model considering all the elastic linear structural elements, except the tie-rod.

3. Tie-rods are modeled by bar elements.

The simplified model allows taking into account the shear effects, which come from ship mooring or transverse crane loading due to the wind in further studies. On the other hand, this model also allows following the mechanical behavior of the wharf and accomplishing simulations with probabilistic purposes.

\section{IDENTIFICATION OF THE OVERALL "SOIL-ROD-ANCHORING PLATE" STIFFNESS}

\subsection{Steps of the flowchart}

To identify the variable $k\left(\theta \mid R_{\Delta H}\right)$ representing the tierods stiffness, three steps are considered:

1. First step: estimation of the variation of deterministic embankment loading during a falling tide, called tide loading $\Delta F_{T L}\left(R_{\Delta H}\right)$, by knowing the filtered random loads $\Delta F\left(x_{i}, \theta \mid R_{\Delta H}\right)$ in tie-rods from Equation (13). Equation (11) is used for solving the $2 \mathrm{D}$ model by replacing $F_{r}\left(x_{i}\right)$ by $\Delta F_{T L}\left(R_{\Delta H}\right)$ and assuming a deterministic stiffness value $k_{d}$ for the random variable $k(\theta)$. Here, oll is the linear elastic model of the beam and the springs.

2. Second step: computing events $k\left(\theta \mid R_{\Delta H}\right)$ by knowing $\Delta F_{T L}\left(R_{\Delta H}\right)$ and $\Delta F\left(x_{i}, \theta \mid R_{\Delta H}\right)$.

3. Third step: identification of the distribution of $k\left(\theta \mid R_{\Delta H}\right.$ ) by using PC expansion (see the following Section 7.3).

Note that the first step is needed because of the lack of knowledge on the earth pressure loading (Schoefs et al., 2004; Yáñez-Godoy et al., 2008b). The deterministic value of $k_{d}$ is assumed to be $61.9 \mathrm{MN} / \mathrm{m}$ : it is a reasonable mean value because it corresponds to the stiffness of a tie-rod perfectly embedded in the anchoring plate without surrounding soil. In fact, the presence of soil tends to increase the stiffness while the possible elastic displacement of the anchoring plate decreases this stiffness.

\subsection{First step: estimation of the tide loading}

Following the flowchart detailed in subsection 7.1, the tide loading $\Delta F_{T L}\left(R_{\Delta H}\right)$ is computed by inverse analy- sis. The corresponding optimization problem is given by the least squares method

$$
\begin{gathered}
\Delta F_{T L}\left(R_{\Delta H}\right)=\underset{\Delta F_{T L}}{\operatorname{argmin}}\left(\sum _ { i = 1 } ^ { n } \left(\Delta F^{c}\left(x_{i}, \Delta F_{T L}\left(R_{\Delta H}\right), k_{d}\right)\right.\right. \\
\left.\left.-\overline{\Delta F}\left(R_{\Delta H}\right)\right)^{2}\right)
\end{gathered}
$$

where $\Delta F^{c}\left(x_{i}, \Delta F_{T L}\left(R_{\Delta H}\right), k_{d}\right)$ is the variation of loading in the tie-rod at abscissa $x_{i}$ resulting from a computation with the deterministic 2D model (see Section 6.2) using a tide loading $\Delta F_{T L}\left(R_{\Delta H}\right)$ and $k_{d}$ equal to 61.9 $\mathrm{MN} / \mathrm{m}$; values of $\overline{\Delta F}\left(R_{\Delta H}\right)$ are given in Table 1 . Note that the sample of realizations in each range $R_{\Delta H}$ has quite the same size $m$, so that the random variable under study can be considered as uniformly distributed. Equation (14) is solved using a simplex method (Nelder and Mead, 1965). Applying this approach for the four ranges $r$ of $R_{\Delta H}$, the following four values of $\Delta F_{T L}\left(R_{\Delta H}\right)$ are obtained: $64,77,87$, and $111 \mathrm{kN}$.

\subsection{Second step: building of the sample for $k$}

For a given $R_{\Delta H}$ and by knowing $\Delta F_{T L}\left(R_{\Delta H}\right)$ computed from Equation (14) and the filtered sample of $\Delta F\left(x_{i}, \theta \mid R_{\Delta H}\right)$ deduced from Equation (13), each event $k\left(\theta_{l} \mid R_{\Delta H}\right)$ is solution of the following optimization problem

$$
\begin{aligned}
k\left(\theta_{l} \mid R_{\Delta H}\right)=\underset{k}{\operatorname{argmin}}( & \sum_{i=1}^{n}\left(\Delta F\left(x_{i}, \theta_{l} \mid R_{\Delta H}\right)\right. \\
& \left.\left.-\Delta F^{c}\left(x_{i}, \Delta F_{T L}\left(R_{\Delta H}\right), k\right)\right)^{2}\right)
\end{aligned}
$$

where $\Delta F^{c}\left(x_{i}, \Delta F_{T L}\left(R_{\Delta H}\right), k\right)$ is the variation of loading in tie-rod of abscissa $x_{i}$ resulting from a finite element computation of displacement $u_{i}$ with the deterministic 2D model having stiffness $k$.

The set of events for $k\left(\theta \mid R_{\Delta H}\right)$ is thus deduced from the solution of $m$ inversed problem, where $m$ is the size of the samples of $\Delta F\left(x_{i}, \theta \mid R_{\Delta H}\right)-(m \approx 20)$. This problem is solved by using the same simplex algorithm as above.

The probability distribution of the variable $k(\theta)$ is assessed using all events $k\left(\theta_{l} \mid R_{\Delta H}\right)$, as each coefficient range $R_{\Delta H}$ has the same probability of occurrence (uniformly distributed). Figure 10 shows the probability distribution histogram of $k(\theta)$. The two first statistical moments $\mu_{k}$ and $\sigma_{k}$ are, respectively, $61.2 \mathrm{MN} / \mathrm{m}$ and $9.1 \mathrm{MN} / \mathrm{m}$.

\subsection{Third step: identification using PC decomposition}

As the probabilistic analysis of the input variable $k(\theta)$ has shown that its distribution does not follow a 


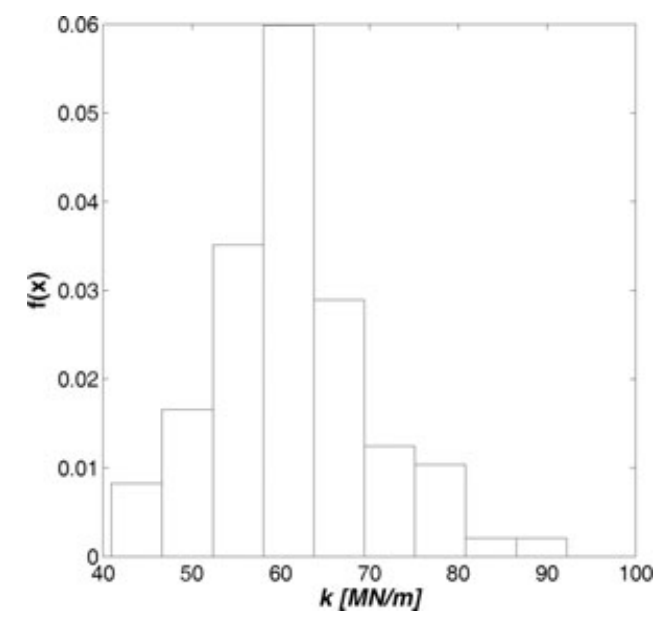

Fig. 10. Probability distribution histogram of $k$.

predefined probability density function and the input uncertainties are large, the PC decomposition is chosen for the identification of the random variable $k(\theta)$.

Let us first consider a PC of order 2. Figure 11a illustrates the variations of $-\log (L(\kappa))$ on the circle with radius 1 . The following parameterization of the hypersphere is adopted by introducing the angular parameter $\phi$

$$
\left\{\begin{array}{l}
k_{1}^{*}=\cos (\phi) \\
k_{2}^{*}=\sin (\phi)
\end{array} \quad \text { with } \quad \phi \in[0 ; 2 \pi]\right.
$$

The function $-\log (L(\phi))$ is reported in Figure 11b where the minimum of the likelihood function can be localized by using the random search algorithm.

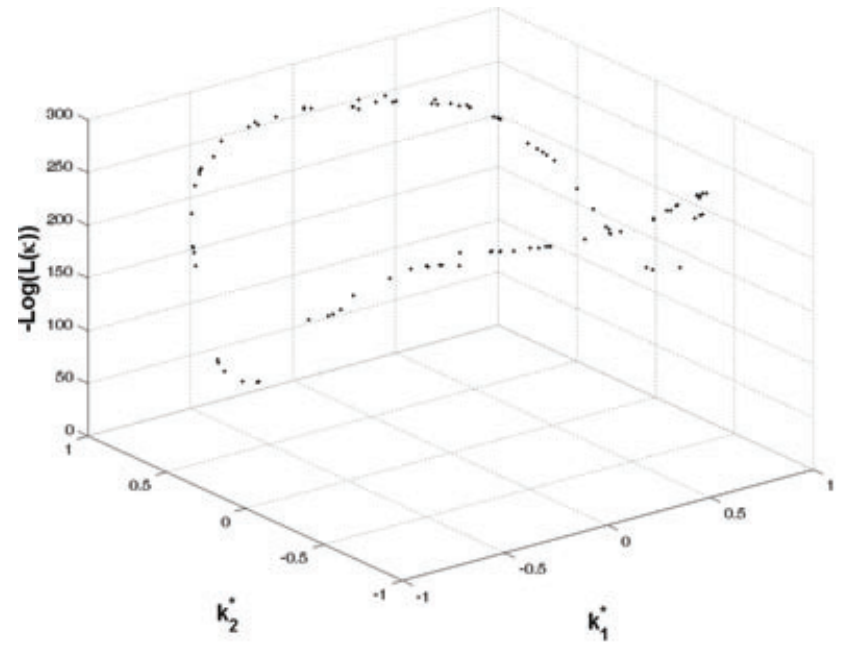

(a)
The solution of the optimization problem is not unique (Figure 11b): three different locations of the solution are observed, two on the boundary and one in the center of the function, around $\phi=3$. The three values are all mathematical solutions of the problem and they give the same representation of the random variable. As the minimum values on the boundaries are not guaranteed to be the real localization of the minimum, they are discarded and only the central minimum is considered. In addition, the central minimum can assume two opposite values, due to the symmetric distribution of the germ $\xi$ and to the symmetry of Hermite polynomials. By the way, both values are physically reasonable because they refer to the same minimum location. In other terms, from Equation (6), if $\phi$ is solution, $\pi-\phi$ is also solution. For example, the following sets of PC coefficients lead to the two statistically identical random variables

$$
\begin{gathered}
k(\theta)=\mu_{k}+\sigma_{k}\left(k_{1}^{*} h_{1}(\xi)+k_{2}^{*} h_{2}(\xi)\right) \\
k(\theta)=\mu_{k}+\sigma_{k}\left(-k_{1}^{*} h_{1}(\xi)+k_{2}^{*} h_{2}(\xi)\right)
\end{gathered}
$$

Let us now consider a $\mathrm{PC}$ of order 3 . To parameterize the hypersphere, two angular parameters $\theta$ and $\phi$ can be introduced

$$
\left\{\begin{array}{l}
k_{1}^{*}=\cos (\theta) \cos (\phi) \\
k_{2}^{*}=\cos (\theta) \sin (\phi) \quad \text { with } \theta \in\left[-\frac{\pi}{2} ; \frac{\pi}{2}\right] \text { and } \phi \in[-\pi ; \pi] \\
k_{3}^{*}=\sin (\theta)
\end{array}\right.
$$

Figure 12 illustrates the function $-\log (L(\theta ; \phi))$ and its isocontour. The figure shows where the minimum of the likelihood function is localized. As for the order 2,

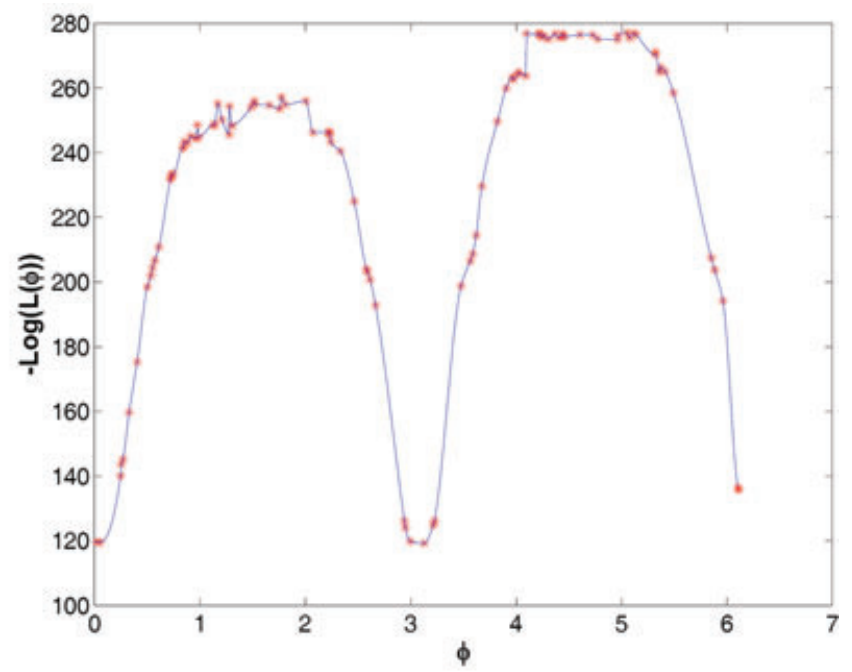

(b)

Fig. 11. Variations of $-\log (L(\kappa))$. (a) With the couple $\left(k_{1}^{*} ; k_{2}^{*}\right)$. (b) With the angular parameter $\phi$. 

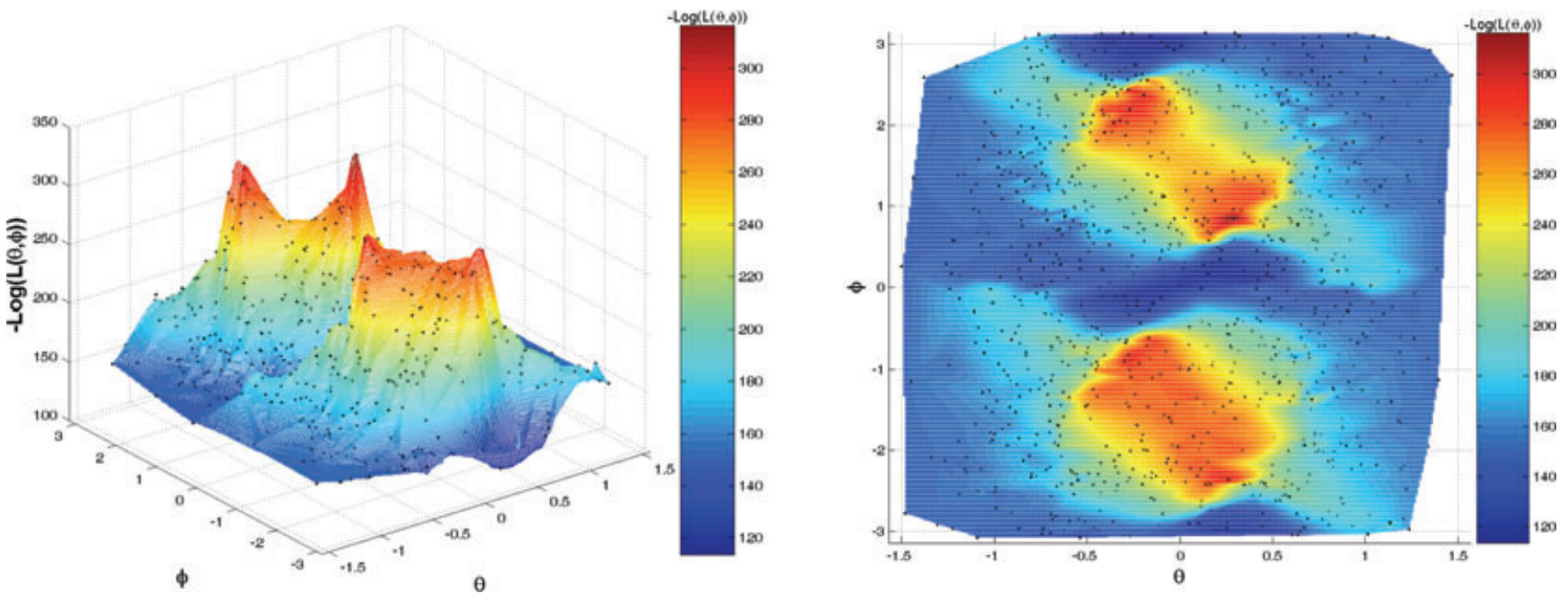

Fig. 12. Function $-\log (L(\theta ; \phi))$.

Table 2

PC coefficients solution of the optimization problem

\begin{tabular}{llll}
\hline PC order & \multicolumn{1}{c}{$k_{i}^{*}[M N / m]$} & $-\log (L(\kappa))$ & \multicolumn{1}{c}{$k_{i}[M N / m]$} \\
\hline 1 & & 120.11 & $k_{0}=61.2$ \\
& & & $k_{1}=9.1$ \\
2 & $k_{1}^{*}=1$ & {$[118.73 ; 118.89]$} & $k_{0}=61.2$ \\
& $k_{1}^{*} \in[-0.9981 ;-0.9965]$ & & $k_{2} \in[0.0699 ;-9.0554]$ \\
& $k_{2}^{*} \in[0.0621 ; 0.0833]$ & {$[117.02 ; 117.22]$} & $k_{0}=61.2$ \\
& & & $k_{1} \in[-8.9600 ;-8.8522]$ \\
& $k_{1}^{*} \in[-0.9860 ;-0.9741]$ & & $k_{2} \in[0.5916 ; 0.8512]$ \\
& $k_{2}^{*} \in[0.0651 ; 0.0937]$ & $k_{3} \in[-1.8876 ;-1.2899]$ \\
\hline
\end{tabular}

the solutions on the boundary are not considered. In this case, the solutions of the optimization problem are four. In fact, if $(\theta ; \phi)$ is a solution, $(\theta ; \pi-\phi),(\theta ;-\phi)$, and $(-\theta ; \phi)$ are solutions too.

Particular solutions $k_{i}^{*}$ and $k_{i}$ are given in Table 2 as well as the relative $95 \%$ confidence intervals. Note that the interval of confidence is a probability due to the flat shape of the likelihood function. In addition, the mean and standard deviation of $k(\xi(\theta))$ are identical to those computed in Section 7.3 from the statistical distribution. The interest of this method based on PC decomposition comes from the fact that complex distributions are fitted without a priori knowledge on the probability density functions and that the variables are in the appropriate format for stochastic finite element computations. Thus, the authors have estimated the reliability of wharfs in various conditions (storms, corrosion) on the basis of this modeling (Yáñez-Godoy et al., 2008a, 2008c).

The probability density functions of the obtained PC decompositions are plotted in Figure 13a; they show convenient fittings of the statistical distribution of $k$. Also, several predefined probability density functions (normal, lognormal, and Gumbel laws) have been tested and reported in Figure 13b. Finally, Table 3 shows a comparison between all the minimum of the likelihood functions obtained from the different approaches.

\section{ROBUSTNESS OF THE PROPOSED PROCEDURE}

This article has presented the complexity of wharf building and behavior. The strategy of the long-term monitoring, which aims to characterize the behavior under horizontal loading, has also been addressed. The analysis of data has allowed modeling the stochastic field of variation of loading during a tide assuming ergodicity with time. Furthermore, a mechanical modeling has been addressed to find a relationship between external loading and measured normal loads in tie-rods. 


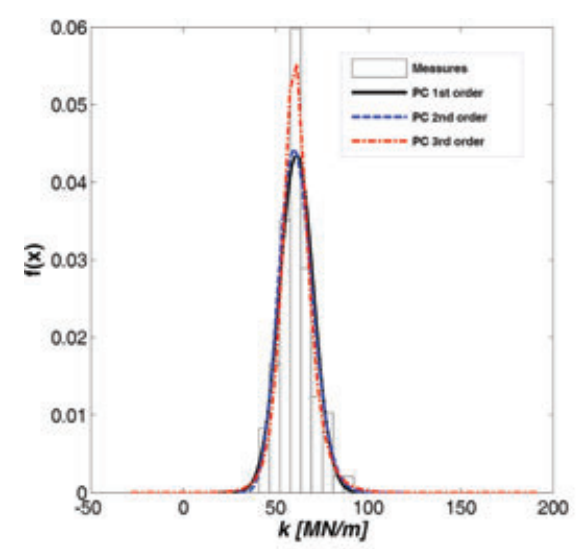

(a)

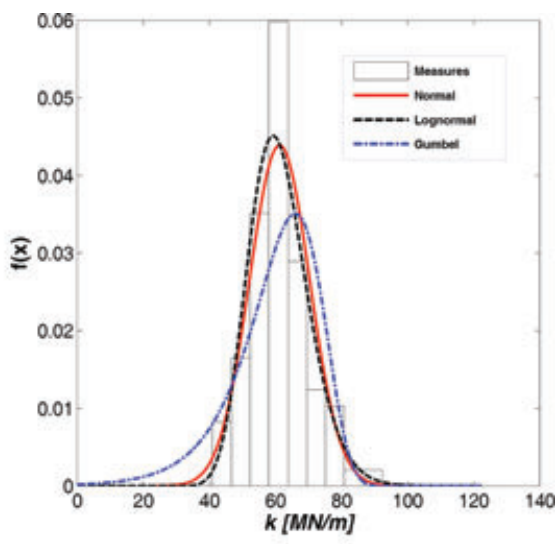

(b)

Fig. 13. Statistical distribution of $k$ for the Cheviré wharf. (a) Fitting with a polynomial chaos. (b) Fitting with several predefined probability density functions.

Table 3

Minimum of the likelihood functions for several fittings

\begin{tabular}{lc}
\hline Fitting & Minimum of the likelihood function \\
\hline PC 1st order & 120.11 \\
PC 2nd order & 118.81 \\
PC 3rd order & 117.12 \\
Normal pdf & 120.14 \\
Lognormal pdf & 118.73 \\
Gumbel pdf & 135.43 \\
\hline
\end{tabular}

Note: pdf, probability density function.

A step-by-step inverse analysis has been performed to identify the parameters of the distribution, using the assumption that the stiffness of the "Soil-Rod-Anchoring Plate" could be modeled by a unique random variable, spatially independent.

An original identification procedure has been suggested: it is based both on maximum likelihood estimate and on the one-dimensional PC decomposition. This method avoids assuming a prior distribution function and helps to systematize the identification from a database. Finally, this method provides a format suitable for direct stochastic finite element analysis. It is useful for reliability updating (Yáñez-Godoy et al., 2008 c) or prediction of probability of failure in time (Yáñez-Godoy et al., 2008a).

The robustness and the generality of the proposed analysis are demonstrated through the application to other complex structures, when a mechanical model and data from a structural monitoring are available. In the following, a synthesis of the results obtained from another monitored wharf (TMDC-4) located in Nantes harbor, not far from the Cheviré wharf is presented as an example. Both wharfs are very similar structures but they differ by the technological anchoring device. In the case of TMDC-4, tie-rods are fastened to the backwharf wall by a ball-joint; during the laying down of the tie-rods, this anchorage device can present a gap $\delta_{0}$ that leads to very light loads in case of wharf displacement. The same number of tie-rods are instrumented but for TMDC-4 a couple of vibrating wire strain gauges have been used for each tie-rod. Both monitoring setups have shown a small evolution in time of the medium-term load variations in the tie-rods, due to the embankment loading and the in-service conditions and to the seasonal cycles of the tide. The analysis of the spatial load variation has shown an important scatter from a tie-rod to another that differs a lot from the theoretical hypothesis assumed at the design stage. The comparison of the results has shown that the sensitivity of the tie-rods to the tide along the TMDC- 4 wharf is more marked than for the Chevire wharf because of different fastening devices. The analysis of the TMDC-4 quay has to take into account also this additional source of uncertainty, so that an additional random variable $\delta_{0}\left(x_{i}, \theta\right)$, representing the laying down of each tie-rod, has been considered in the mechanical model. The two random variables $k\left(x_{i}, \theta\right)$ and $\delta_{0}\left(x_{i}, \theta\right)$ are considered as independents and they are identified with the proposed inverse method by using the short-term and the mediumterm behaviors, respectively. The mechanical stiffness of the loaded tie-rods in similar structures with different technological anchoring devices is of the same order, so to confirm the reliability of the measurements systems. Finally, a first-order, second-order, and third-order PC are considered for the decomposition analysis. A comparison of the resulting probability distribution of $k\left(x_{i}\right.$, $\theta$ ) from both wharfs is possible. Figure 14 shows that a 


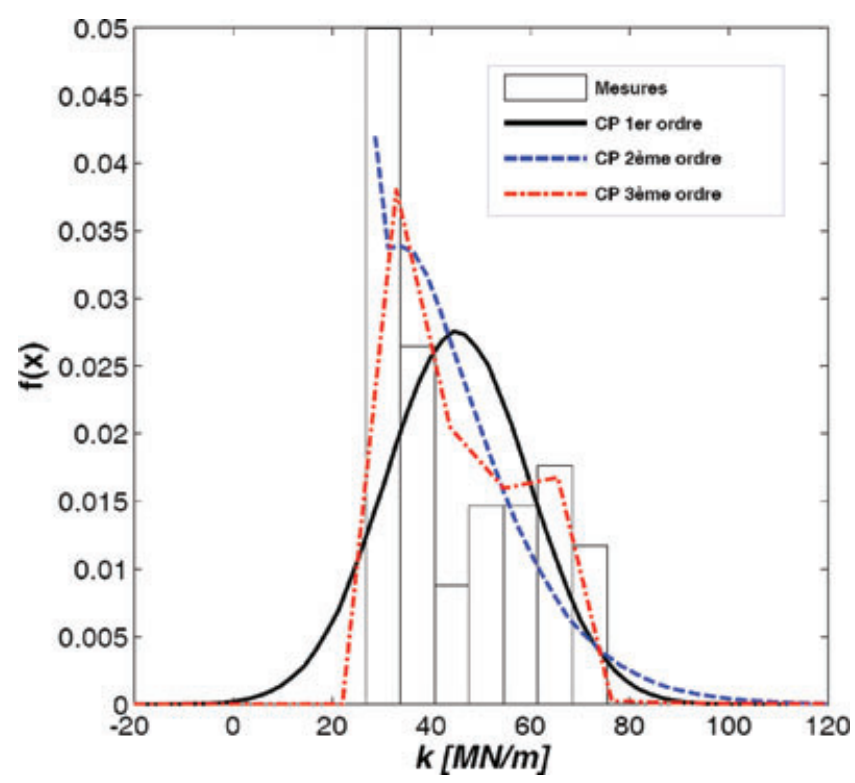

Fig. 14. Statistical distribution of $k$ for the TMDC-4 wharf.

third-order PC allows catching the trend of the bimodal probability histogram obtained for the stiffness random variable on the TMDC-4 wharf.

Figures 13a and 14 allow discussion about the order of the PC decomposition. The identification procedure does not allow a detailed analysis of the queues of the distribution due to the scarcity of the available experimental samples. This article is mainly focused on catching at least the global trend of the probability distribution and the peaks of the histograms. PC of first order gives a bad fitting of the histogram, in particular when a bimodal distribution is required, because it is very close to the normal distribution centered on the mean experimental value. $\mathrm{PC}$ of second order is still insufficient to catch the good trend because it is substantially like the PC of first order for the Chevire wharf and it is able to describe just the first peak for the TMDC-4 wharf. Finally, the PC of third order gives a good representation of the global distribution and better catches the peaks also for the bimodal distribution. The PC of third order has been considered good enough for the goals of this article. In addition, other works have already demonstrated a good convergence when a third-order decomposition is chosen (Schoefs et al., 2009). The consideration of the stochastic model uncertainties associated to limited data could improve the results in comparison with the study of higher PC orders. As a consequence, further developments will be addressed to introduce model uncertainties on the PC decomposition of first, second, and third order (Ghanem and Doostan, 2006).

\section{ACKNOWLEDGMENTS}

This work is supported by the European Community and FEDER founds within the MEDACHS Interreg IIIB (Atlantic space, project $\mathrm{N}^{\circ} 197$ ) (MEDACHS: Marine Environment Damage to Atlantic Coast Historical and transport works or Structures: Methods of diagnosis, repair and of maintenance) (web site: http://www.medachs.u-bordeaux1.fr). The authors would like to thank the Port Authorities of Nantes St Nazaire, for their technical support and expert judgment. The second author's work was financed by a CONACYT PhD studentship (Mexico).

\section{NOTES}

1. In France, the oscillation amplitude of semidiurnal tide is associated with a coefficient named tide coefficient CMAR (french acronym for coefficient de marée).

2. The Tides Annual is published by PANSN and it includes nearby ports: Saint-Nazaire, Donges, Cordemais, Le Pellerin, and Nantes.

3. Note that coefficients CMAR higher than 100 occur rarely and few data are available.

\section{REFERENCES}

Adeli, H. \& Jiang, X. (2006), Dynamic fuzzy wavelet neural network model for structural system identification, Journal of Structural Engineering, ASCE, 132(1), 102-11.

Adeli, H. \& Jiang, X. (2009), Intelligent InfrastructureNeural Networks, Wavelets, and Chaos Theory for Intelligent Transportation Systems and Smart Structures, CRC Press, Taylor \& Francis, Boca Raton, FL.

Ananthanathan, P. J., Gajan, S., Kanagalingam, T. \& Seneviratne, H. N. (2000), Behavior of laterally loaded piles, Proceedings of the Engineering Jubilee Congress "Engineering Beyond 2000,” University of Peradeniya, Sri Lanka, 103-6.

Bae, H.-R., Grandhi, R. V. \& Canfield, R. A. (2004), Epistemic uncertainty quantification techniques including evidence theory for large-scale structures, Computers \& Structures, 82(13-14), 1101-12.

Beck, J. V. \& Arnold, K. J. (1977), Parameter Estimation in Engineering and Science, John Wiley \& Sons, New York.

Boéro, J., Schoefs, F., Capra, B. \& Rouxel, N. (2009a), Technical management of French harbour structures. Part 1: Description of built assets, Revue Paralia, 2, 6.1-6.11. doi:10.5150/revue-paralia.2009.006.

Boéro, J., Schoefs, F., Capra, B. \& Rouxel, N. (2009b), Technical management of French harbour structures. Part 2: Current practices, needs- Experience feedback of owners, Revue Paralia, 2, 7.1-7.12. doi:10.5150/revue-paralia. 2009.007.

Cheung, S. H. \& Beck, J. L. (2010), Calculation of posterior probabilities for Bayesian model class assessment and averaging from posterior samples based on dynamic system 
data, Computer-Aided Civil and Infrastructure Engineering, 25(5), 304-21.

Delattre, L. \& Mespoulhe, L. (1999), Etude expérimentale du comportement du quai en eau profonde du port de Calais, Rapport 65, Paris, France: Laboratoire Central des Ponts et Chaussées.

Del Grosso, A. (2000), Monitoring of infrastructures in the marine environment, Proceedings of the International Workshop on Structural Control for Civil and Infrastructure Engineering, Paris, France, 107-17.

Del Grosso, A., Inaudi, D. \& Lanata, F. (2000), Strain and displacement monitoring of a quay wall in the Port of Genoa by means of fibre optic sensors, Proceedings of the 2nd ECSC European Conference, Champs-sur-Marne, France, 8 pp. (on CD-Rom).

Desceliers, C., Soize, C. \& Ghanem, R. (2007), Identification of chaos representations of elastic properties of random media using experimental vibration tests, Computational Mechanics, 39, 831-38.

Donahue, M. J., Dickenson, S. E., Miller, T. H. \& Yim, S. C. (2005), Implications of the observed seismic performance of a pile-supported wharf for numerical modeling, Earthquake Spectra, 21(3), 617-34.

Gattermann, J., Bergs, T. \& Rodatz, W. (2001), Modified instrumentation and results of stress and deformation monitoring at the new quay wall construction - Container Terminal Altenwerder, Port of Hamburg, Proceedings of the 8th International Conference on Structural Safety and Reliability-ICOSSAR 2001, Newport Beach, CA, 102 (full paper on CD-Rom).

Ghanem, R. G. \& Doostan, A. (2006), On the construction and analysis of stochastic models: characterization and propagations of the errors associated to limited data, Computational Physics, 217, 63-81.

Ghanem, R. G. \& Spanos, P. (2003), Stochastic Finite Elements: A Spectral Approach, Revised Edition, Dover Publications, NY.

Igusa, T., Buonopane, S. G. \& Ellingwood, B. R. (2002), Bayesian analysis of uncertainty for structural engineering applications, Structural Safety, 24(2-4), 165-86.

Lagarias, J. C., Reeds, J. A., Wright, M. H. \& Wright, P. E. (1998), Convergence properties of the nelder-mead simplex method in low dimensions, SIAM Journal of Optimization, 9, 112-47.

Lanata, F. \& Schoefs, F. (2010), Multi-algorithm approach for identification of structural behaviour of complex structures under cyclic environmental loading, Structural Health Monitoring (in press).

Madhuri, S., Sannasiraj, S. A. \& Sundaravadivelu, R. (2007), Effect of revision of seismic codal provisions on the analysis of berthing structures, IE(I) Journal-CV, 88, 12-17.

Magnan, J-P. (2006), Euro code 7: calcul géotechnique, EditoETI - Sciences et Techniques. Techniques de l'ingénieur, France, C240, pp. 1-8.

Marten, S., Delattre, L., Nguyen, Ph. D. \& Burgeois, E. (2004), The new deep water quay "Port 2000" of Le Havre, France: field monitoring and performance prediction, Proceedings of the 9th International Symposium on Numerical Models in Geomechanics NUMOG IX, Taylor \& Francis Group, London, 565-72.

Martin, N. J. \& Bell, S. I. (1999), The restoration of Shuaiba oil pier, Kuwait, in Proceedings of the International Conference on Monitoring and Control of Marine and Harbour Structures, Genoa, Italy, 123-32.
Matthies, H. G. (2007), Quantifying uncertainty: modern computational representation of probability and applications, in A. Ibrahimbegovic and I. Kozar (eds.), Extreme Man-Made and Natural Hazard in Dynamics of Structures, Springer, Berlin, 105-35.

Moaveni, B., Conte, J. P., \& Hemez, F. M. (2009), Uncertainty and sensitivity analysis of damage identification results obtained using finite element model updating, ComputerAided Civil and Infrastructure Engineering, 24(5), 32034.

Moerman, W., Taerwe, L., De Waele, W., Degrieck, J. \& Himpe, J. (2005), Measuring ground anchor forces of a quay wall with bragg sensors, Journal Structural Engineering, 131, 322-28.

Muhanna, R. L., Zhang, H. \& Mullen, R. L. (2007), Interval finite elements as a basis for generalized models of uncertainty in engineering mechanics, Reliable Computing, 13, 173-79.

Nelder, J. \& Mead, R. (1965), A simplex method for function minimization, The Computer Journal, 7, 308-13.

Nozu, A., Ichii, K. \& Sugano, T. (2004), Seismic design of port structures, Journal of Japan Association for Earthquake Engineering, 4(3), 195-208.

Perrin, F., Sudret, B., Blatman, G. \& Pendola, M. (2007), Use of polynomial chaos expansions and maximum likelihood estimation for probabilistic inverse problems, in Proc. $18^{\text {eme }}$ Congres Français de Mécanique, Grenoble, France, doi:10.4267/2042/15789.

Schoefs, F., Clément, A. \& Nouy, A. (2009), Assessment of ROC curves for inspection of random fields, Structural Safety, 31(5), 409-19.

Schoefs, F., Gerard, B, Casari, P. \& Verdure, L. (2004), Stratégie d'instrumentation pour la gestion optimisée des ouvrages portuaires, in Proc. VIII emes Journées $\mathrm{Na}$ tionales Génie Côtier-Génie Civil, Compiegne, France, 513-20.

Sundaravadivelu, R., Gopala Krishna, M. \& Chellappan, V. (1999), Monitoring the behaviour of diaphragm walls of a dry dock, in Proceedings of the International Conference on Monitoring and Control of Marine and Harbour Structures, Genoa, Italy, 113-22.

Vallone, P. \& Giammarinaro, M. S. (2007), Monitoring of termini imerese harbour (Sicily, Italy) using satellite DInSAR data, in Proceedings of Applied Geophysics for Engineering, Messina, Italy (on CD-Rom).

Verdure, L. (2004), Cadre statistique du suivi en service des ouvrages de génie civil: application e un quai sur pieux, $\mathrm{PhD}$ Thesis, Nantes University, France.

Verdure, L., Schoefs, F., Casari, P. \& Yáñez-Godoy, H. (2005), Uncertainty updating of an on-pile wharf after monitoring, in Proceedings of the 9th International Conference on Structural Safety and Reliability ICOSSAR 2005, Rome, Italy, 1347-54.

Yáñez-Godoy, H. (2008), Mise à jour de variables aléatoires à partir des données d'instrumentations pour le calcul en fiabilité de structures portuaires (Updating of random variables from data monitoring for reliability assessment of harbor structures), PhD Thesis, Nantes University, France.

Yáñez-Godoy, H., Boéro, J. \& Schoefs, F. (2008a), Mediumterm life-cycle monitoring of random behaviour components of in-service pile-supported wharves, in Proceedings of the 1st International Symposium on Life-Cycle Civil Engineering (IALCCE'08), Varenna, Italy, paper Pa_204 (on CD-Rom). 
Yáñez-Godoy, H., Schoefs, F. \& Casari, P. (2008b), Statistical analysis of the effects of building conditions on the initial loadings of on-piles quays, Structural Health Monitoring, 7(3), 245-63.

Yáñez-Godoy, H., Schoefs, F. \& Nouy, A. (2008c), Use of structural monitoring for updating reliability analysis: application on pile-supported wharves, in Proceed- ings of the 4th International ASRANet Colloquium, 2527 June 2008, Athens, Greece, paper 74, 10 pages (on CD-Rom).

Yáñez-Godoy, H., Schoefs, F., Nouy, A. \& Casari, P. (2006), Extreme storm loading on in-service wharf structures: interest of monitoring for reliability updating, Revue Européenne de Génie Civil, 5(10), 565-81. 